\title{
HIGH TEMPERATURE CREEP OF DIRECTIONALLY SOLIDIFIED NI BASE SUPERALLOYS CONTAINING LOCAL RECRYSTALLIZATION
}

\author{
G. Xie, L. Wang, J. Zhang, L. H. Lou \\ Institute of Metal Research, Chinese Academy of Sciences, Shenyang 110016, China \\ Keywords: Recrystallization, Creep, Superalloy, Dislocation
}

\begin{abstract}
High temperature creep of directionally solidified Ni-base superalloys containing local recrystallization (RX) was studied. An almost linear reduction of the creep rupture life was observed with increase of the fraction of local RX on the cross section of the specimen. Creep curves of specimens containing local RX showed that the second and tertiary creep stages were much shorter than those of the original specimens. Moreover, their creep rates slightly increased before reaching the steady state. The change of creep rate is related to the formation and propagation of cracks at the RX grain boundaries according to the observation of the interrupted creep microstructure. The creep mechanisms were discussed based on the dislocation morphology in the vicinity of the RX grain boundaries.
\end{abstract}

\section{Introduction}

Directionally solidified (DS) superalloys possess extremely good elevated temperature capability due to the elimination of highly stressed transverse grain boundaries. For this reason, they are finding widespread use as turbine airfoils in advanced aero-engines and industrial gas turbines [1, 2].

Recrystallization (RX) in DS blades caused either by the residual stresses or by the plastic deformation generated during manufacturing is a well-known issue in the investment casting industry. The effects of applied stress, heat treatment parameters, as well as the microstructural features such as residual eutectics and carbides on RX behaviors in several DS superalloys have been reported [3-6].

It is also generally accepted that local $\mathrm{RX}$ may reduce the mechanical properties of DS superalloys [7-12]. For example, less than half of the creep rupture life of DZ22 alloy can be achieved when there was a surface RX layer induced by shot-peening. The detrimental effect was more pronounced at low temperature/high stress condition [7]. Similar data were also reported by Khan et al. [8]. The creep rupture life of DS MAR-M247 at $850{ }^{\circ} \mathrm{C} / 451 \mathrm{MPa}$ was greatly reduced when a surface RX layer existed. Besides the RX layer induced by shot-peening, local RX showed similar detrimental effect on the creep rupture life of single crystal superalloy SRR99 as reported by Wang [11]. Recrystallization also decreased the fatigue properties of DS superalloys. High cycle fatigue strength of CMSX-4 at $950{ }^{\circ} \mathrm{C}$ and low cycle fatigue strength of CMSX-6 alloy at $980{ }^{\circ} \mathrm{C}$ were all decreased by cellular recrystallization $[4,13]$. Unfortunately, all these investigations were performed in different alloy systems by employing different samples and RX configurations. Systematic information on the effect of RX on mechanical properties of DS superalloys was therefore very limited. Consequently, the quantitative evaluation of the effect of RX is very difficult.

The detrimental effect of RX was interpreted as formation of the weak transverse grain boundaries in DS alloys. However, the detailed studies on microstructural evolution of DS alloys containing local RX during property tests have rarely been conducted. The exact damage mechanism of DS alloy containing local RX remains unclear.

The aim of our present paper is to study the effect of local RX on the high temperature creep properties of two DS superalloys, and trying to explore the role of $\mathrm{RX}$ by monitoring the microstructural evolution during creep. 


\section{Experimental}

The nominal compositions of the DS superalloys studied (DZ125L and DZ17G) are shown in Table I. Alloys were directionally solidified into plate with the size of $220 \times 70 \times 16$ mm using a Bridgman furnace. Details of the DS process were reported elsewhere [14]. The resulted DS slab has an average grain size of $2 \sim 3 \mathrm{~mm}$ and a primary dendrite arm spacing around $300 \mu \mathrm{m}$.

DS slabs were cut into plates by electron discharge machining
(EDM) and indented using Brinell hardness tester on one side. After heat treatment $\left(1220{ }^{\circ} \mathrm{C} / 2 \mathrm{~h} / \mathrm{AC}+1080{ }^{\circ} \mathrm{C} / 4 \mathrm{~h} / \mathrm{AC}+900\right.$ ${ }^{\circ} \mathrm{C} / 16 \mathrm{~h} / \mathrm{AC}$ for DZ125L and $1220^{\circ} \mathrm{C} / 4 \mathrm{~h} / \mathrm{AC}+980^{\circ} \mathrm{C} / 16 \mathrm{~h} / \mathrm{AC}$ for DZ17G), the local RX occurred. The indentation was then carefully removed by grinding. (The specimens with different depth of local RX can be obtained by applying different indentation load and controlling the subsequent grinding process. Detailed procedure of sample preparation was reported in our previous work [12].) The plate specimens were with $50 \times$ $5 \times 2 \mathrm{~mm}$ gauge section for creep tests, and $15 \times 5 \times 2 \mathrm{~mm}$ gauge section for creep rupture tests.

Table I Nominal chemical composition in wt\% of alloys investigated.
\begin{tabular}{l|l|l|l|l|l|l|l|l|l|l|l} 
& Cr & Co & W & Mo & Al & Ti & Ta & V & C & B & Ni \\
\hline DZ125L & 9 & 10 & 7 & 2 & 5 & 3.5 & 4 & -- & 0.1 & 0.01 & Bal. \\
\hline DZ17G & 9 & 9.5 & -- & 3 & 5 & 4.5 & -- & 0.7 & 0.2 & 0.016 & Bal.
\end{tabular}

The effect of depth of local RX on high temperature creep rupture properties was studied. Tests were performed at 980 ${ }^{\circ} \mathrm{C} / 235 \mathrm{MPa}$ for DZ125L and at $980{ }^{\circ} \mathrm{C} / 175 \mathrm{MPa}$ for DZ17G. In order to monitor the microstructural evolution during creep, the creep tests were performed at $980{ }^{\circ} \mathrm{C} / 235 \mathrm{MPa}$ using DZ125L. Some of the creep tests were also interrupted at different stages. The stress axis was parallel to the DS direction, and specimens without local RX were chosen as reference materials in all tests.

Specimens for optical microscopy and scanning electron microscope (SEM) observation were prepared by the standard metallographic procedure. Transmission electron microscope (TEM, Philips TECNAI 20) was employed to characterize the dislocation pattern during creep. After interrupted creep tests, small plate was cut from the RX site as well as the un-recrystallized region of the specimen. The plane of the small plate was parallel to the specimen surface. These small plates were first sliced into $50 \mu \mathrm{m}$ discs and then ion polished into TEM foils.

\section{Results}

\section{$\underline{\text { Microstructure of RX after Heat Treatment }}$}

The morphology of RX under the indentation after heat treatment was shown in Figure 1. The local RX formed mainly in the dendritic core region, leaving the interdendritic region un-recrystallized. Different specimens with different load had similar morphology but different maximum depth of the RX under the surface. SEM observation revealed that very fine $\gamma^{\prime}$ particles precipitated in the RX grains and coarse $\gamma^{\prime}$ particles formed along the RX grain boundary after heat treatment (Fig. 1b). This type of RX morphology resulted from the pinning effect of un-dissolved large $\gamma^{\prime}, \gamma / \gamma^{\prime}$ eutectics, and/or carbides at interdendritic region during heat treatment has been observed in many superalloys $[4,6]$.

\section{Effect of RX on Creep Rupture Life}

In order to quantitatively evaluate the effect of $\mathrm{RX}$ on creep rupture life, data obtained from present experiments as well as from literature was examined. The normalized creep rupture life of different DS superalloys was plotted as a function of transverse RX area fraction (TRF) as shown in Figure 2 [12]. Normalized creep rupture life equals to the creep life of a specimen divided by the average creep life of the specimens without any local RX. TRF is defined as $A_{R X} / A$, where $A_{R X}$ is the area of the surface $\mathrm{RX}$ on the cross section which is perpendicular to the stress direction, and $A$ is the area of the cross section of the specimen. The local RX reduced the creep rupture life of the DS superalloys dramatically (Figure 2). Almost a linearly reduction of the creep rupture life with the TRF was found. 

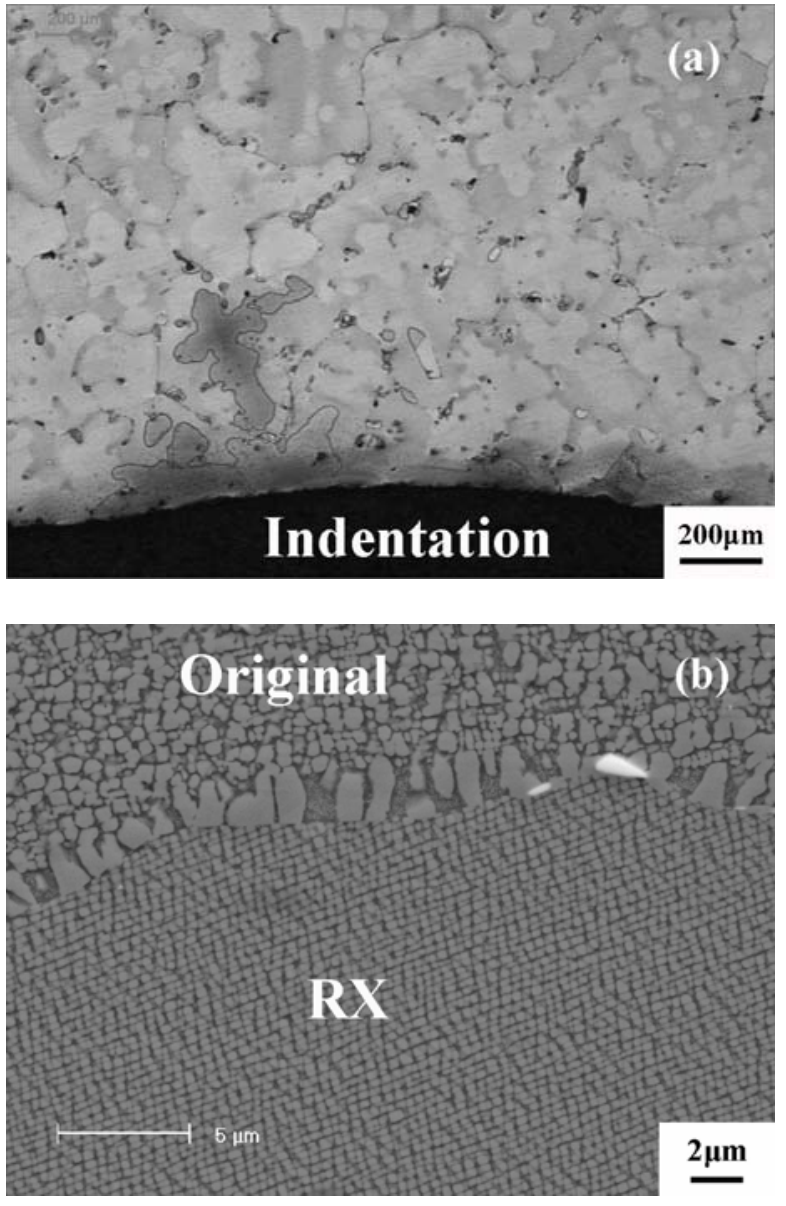

Figure 1: Morphology of local RX in DZ125L after heat treatment $(750 \mathrm{~kg}$ indentation load). (a) low magnification showing the isolated RX grains distributed primarily at the dendrite core and (b) SEM image showing the coarse $\gamma^{\prime}$ formed at the front of RX grain boundary.

\section{Comparison of Creep Curves}

Creep curves of two specimens of DZ125L (specimen A, “good” specimen without RX and specimen B containing local $\mathrm{RX}$ within the gauge section) were compared in Figure 3 (a). The maximum depth of local RX in specimen B is about 1000 $\mu \mathrm{m}$. Three regimes were observed, namely, a very short primary creep, followed by secondary (steady) creep and tertiary (accelerated) creep. The secondary and tertiary creep regimes were reduced when there was local RX in the specimen. The creep rate of different specimens as a function of time was shown in Figure 3(b). It is interesting to note that after primary creep, the creep rate of specimen B slightly increased before reaching the steady state. The tertiary creep regime for

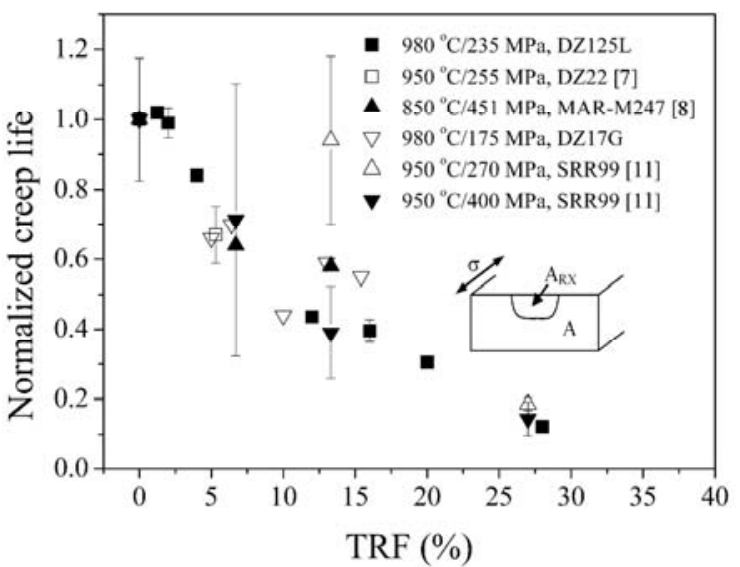

Figure 2: Normalized creep rupture life as a function of TRF. Normalized creep rupture life equals to the creep life of a specimen divided by the average creep life of the specimens without any local RX. TRF is defined as $A_{R X} / A$, where $A_{R X}$ is the area of the surface $\mathrm{RX}$ on the cross section, and $A$ is the area of the cross section of the specimen (see the insert) [12].
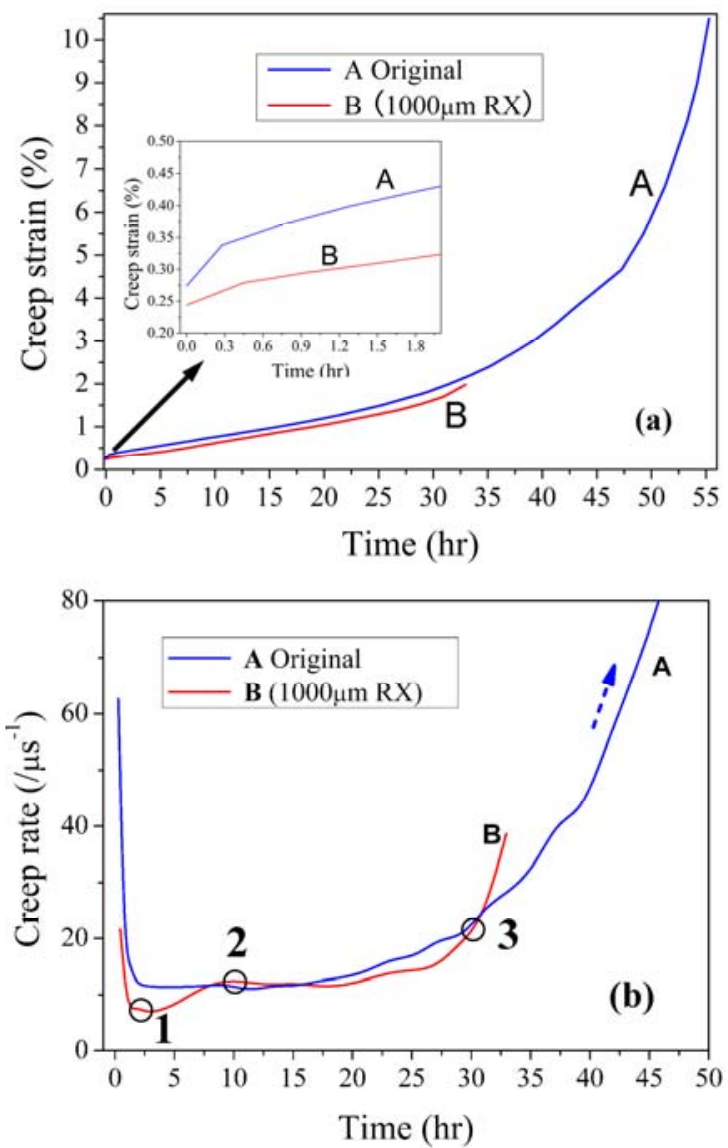

Figure 3: Comparison of (a) creep curves of DZ125L alloy without (A) and with (B) local RX and (b) creep rate of alloy 
DZ125L as a function of time. Circles in the figure indicate the interrupted creep tests of curve B. Creep tests performed at 980 ${ }^{\circ} \mathrm{C} / 235 \mathrm{MPa}$.

specimen B was extremely short as shown in Figure 3(b). On the other hand, the "good" specimen showed a comparable steady state during creep, but a very long tertiary creep regime (more than one half of the overall creep life).

\section{$\underline{\text { Microstructural Evolution during Creep of RX Specimens }}$}

\section{Primary Creep}

The microstructure interrupted at primary creep regime (point " 1 " in Figure 3b) was shown in Figure 4. At this stage, only a few short cracks developed at the transverse RX grain boundaries. Most part of the RX/matrix interface was
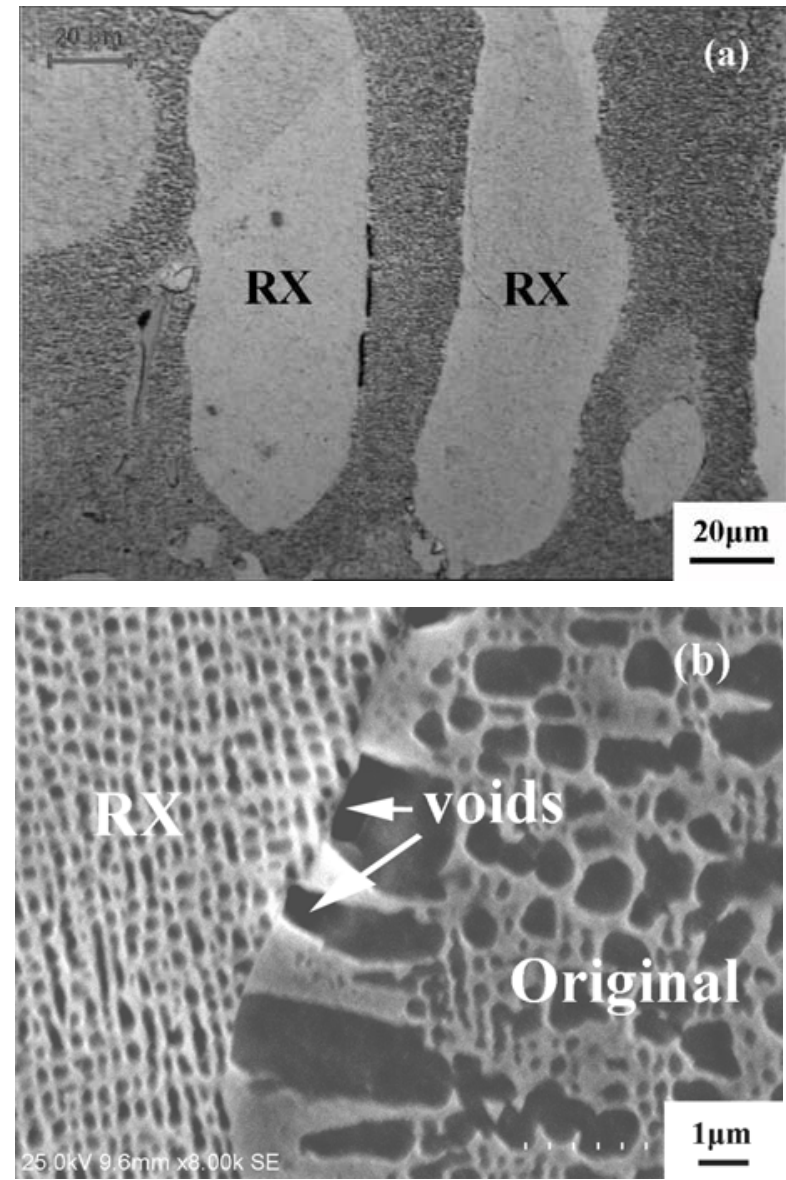

Figure 4: (a) RX grain boundaries after interrupted creep test (point "1" in Figure 3b). (b) Voids observed at the transverse RX grain boundaries. Stress axis is parallel to the horizontal direction of the figure. undestroyed (Fig. 4a). SEM observation showed that a few voids formed along the transverse RX grain boundaries (Fig. $4 b)$. The initiation site of these voids is mainly at the interface between original $\gamma$ matrix and $\mathrm{RX}$ grain.

\section{Steady State Creep}

Figure 5 shows the optical micrograph of specimen interrupted at the beginning of the steady state (point "2" in Figure 3b). Comparing to Figure 4a, the number of microcracks increased at the transverse RX grain boundaries and tended to connect with each other. In this case, the most vulnerable site was the grain boundary between two recrystallized grains where large amount of the residual eutectics located.

TEM observation demonstrated that deformation was inhomogenous at this stage. Within the RX grain, in most area, the coherent cuboidal $\gamma^{\prime}$ distributed uniformly and very low dislocation density was observed (Figure 6a). However, dense dislocations formed in the $\gamma$ matrix in some local regions (Figure 6b). Similar dislocation pattern was found in the original DS material. Figure 7 shows the region with high dislocation density in the original DS material. As for RX grain boundary, dense dislocations formed locally in the $\gamma$ matrix outside the RX grain boundary (Figure 8a). Meanwhile, most of the RX grain boundaries were free of dislocation. Occasionally, dislocation formed in the $\gamma$ matrix of the original DS material was observed to move into the RX grain boundary (Figure 8b).

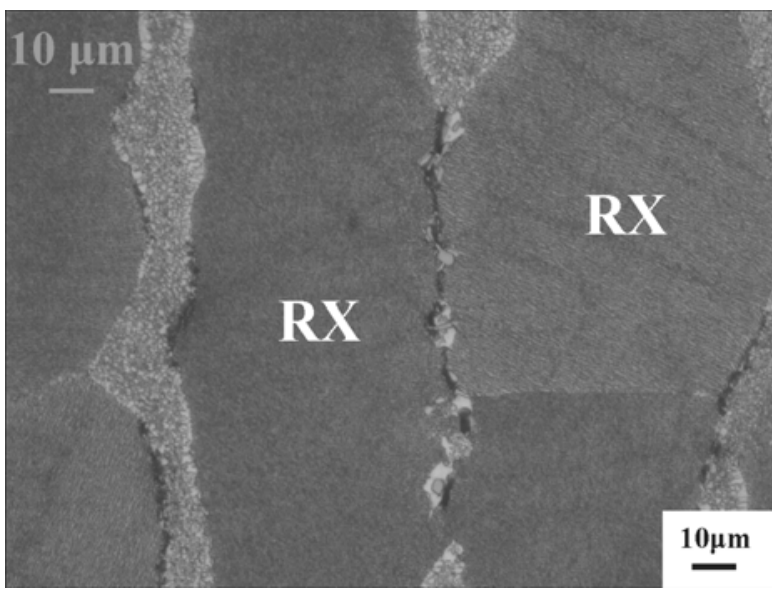

Figure 5: Microstructure of the specimen interrupted at the steady state (point “2” in Figure 3b). Stress axis is parallel to the horizontal direction of the figure. 

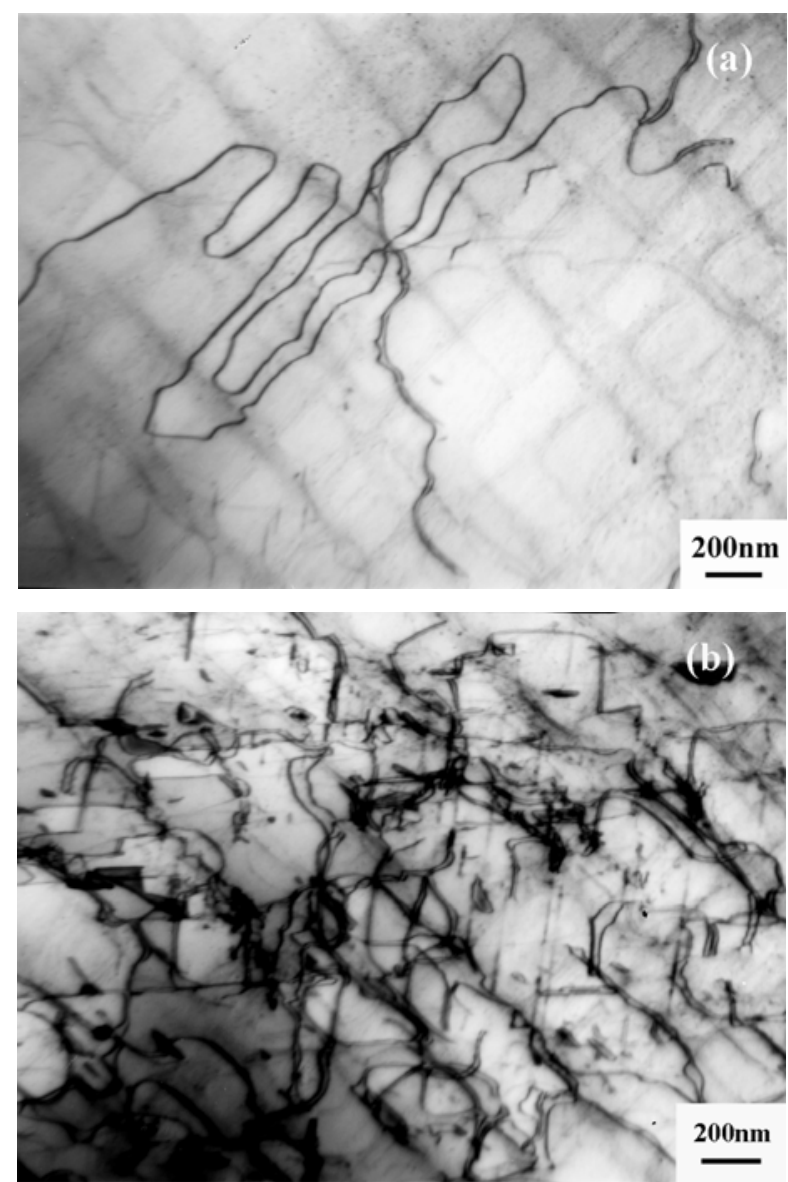

Figure 6: TEM micrograph of interrupted creep specimen (point " 2 " in Figure $3 \mathrm{~b}$ ) showing the dislocation distribution inside the $\mathrm{RX}$ grain. (a) most area are free of dislocation and (b) dense dislocation formed locally.

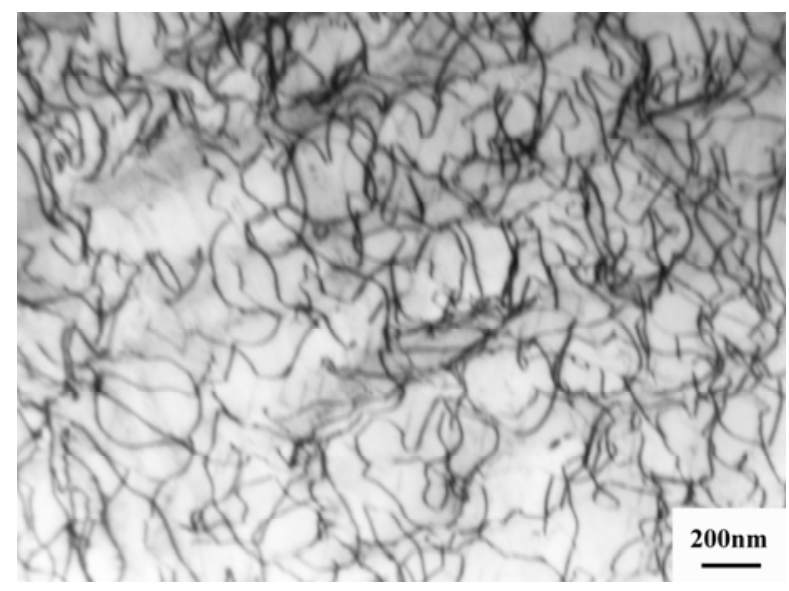

Figure 7: TEM micrograph of region with high dislocation density in the un-recrystallized matrix. Sample cut from the interrupted creep specimen (point “2” in Figure 3b).

\section{Tertiary Creep}

Several large cracks along the RX grains connected with each other at the beginning of tertiary (accelerated) creep stage. As shown in Figure 9a, these cracks only crossed a very small fraction of the original DS material. Careful observation at the site between the recrystallized and un-recrystallized region indicated that the cracks shown in Figure 9a began to propagate into the original DS material (Figs. 9b and 9c). At this stage, cracks were also observed at the transverse segment of the original DS grain boundaries (Figure 9d).
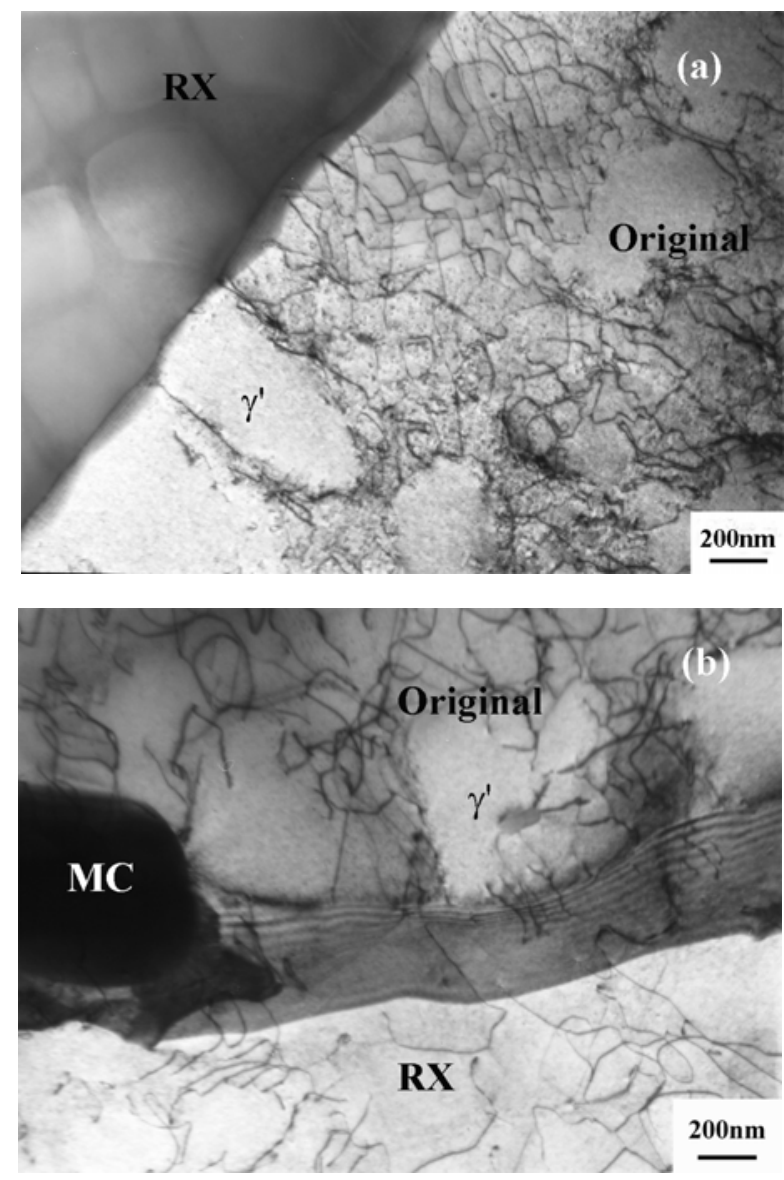

Figure 8: TEM micrograph of RX grain boundary in the interrupted creep specimen (point "2" in Figure 3b). (a) Dislocations tangled at local RX grain boundary and (b) $\gamma$ matrix dislocations moved into the RX grain boundary.

Figure $10 \mathrm{a}$ and $\mathrm{b}$ is the TEM micrograph showing the dislocation pattern in the vicinity of the RX grain boundary observed in interrupted creep specimen at tertiary (accelerated) creep stage (point “3” in Figure 3b). Dislocation density increased in both side of the grain boundary. Dislocation 

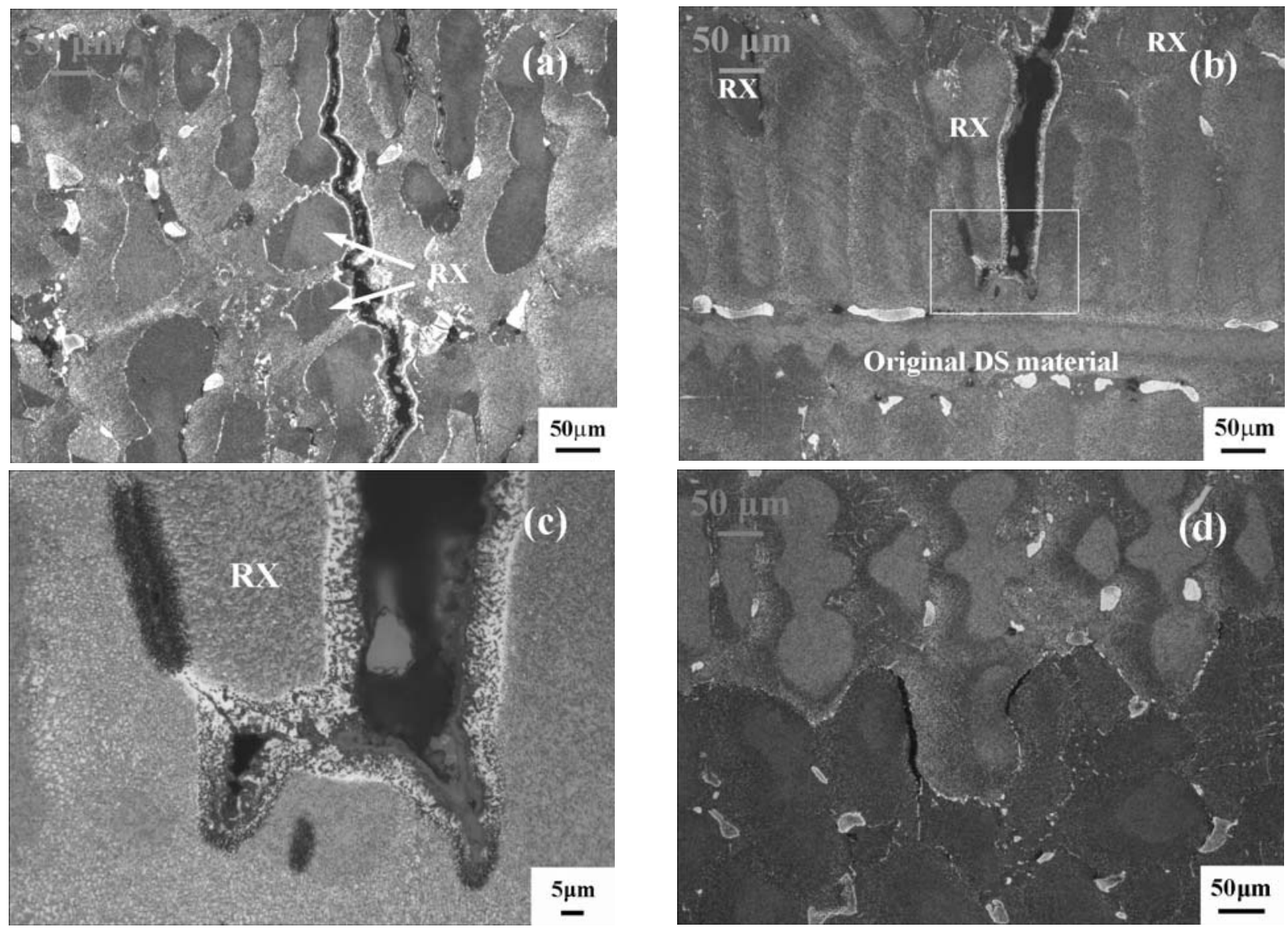

Figure 9: Microstructure of the specimen interrupted at the beginning of the tertiary creep stage (point “3” in Figure 3b). (a) Cracks along the RX grain boundaries connected with each other. (b) Low magnification and (c) high magnification showing the cracks at RX grain boundary propagated into the unrecrystallized DS material. (d) Crack initiated at the transverse segment of the original DS grain boundary.

network can be observed in the $\gamma$ channel in Figure 10b, and the $\gamma^{\prime}$ particle had also been sheared by the dislocations. In the original DS material that was far from the recrystallized region, $\gamma$ ' particles had been rafted (Fig. 10c).

\section{Discussion}

Between the primary creep and the beginning of steady state creep, deformation in the RX grain and original DS matrix was inhomogeneous (Figure 6-8). Creep deformation was accomplished by bowing the dislocations through the $\gamma$ channels. The dislocations generated from different direction (vertical or horizontal matrix channel) would tangle with each other at the RX grain boundary. Figure 11 schematically illustrates the dislocation pattern. Similar dislocation arrangement had been demonstrated in CMSX-3 single crystal superalloy during creep [15]. Dislocations were also observed to move into the RX grain boundary in Figure 8b. Such dislocation configuration may induce the formation of vacancies [16, 17]. The dislocation tangle and diffusion of vacancy along RX grain boundary eventually led to the formation of micro-voids as shown in Figure $4 \mathrm{~b}$. The diffusion and connection of such micro-voids along grain boundaries is accelerated at high temperature by the aid of the applied stress. Consequently, small micro-cracks were forming at the transverse RX grain boundaries, which resulted in the increase of creep rate during this stage of creep.

A relatively stable creep rate was observed after this stage. The whole steady state (secondary creep regime) was actually the stage of crack propagation and connection within the RX region. During this stage, most of the cracks propagated along the transverse RX grain boundaries and stopped at the original DS 
material. The original DS material almost remained undestroyed. TEM observation found local regions with high
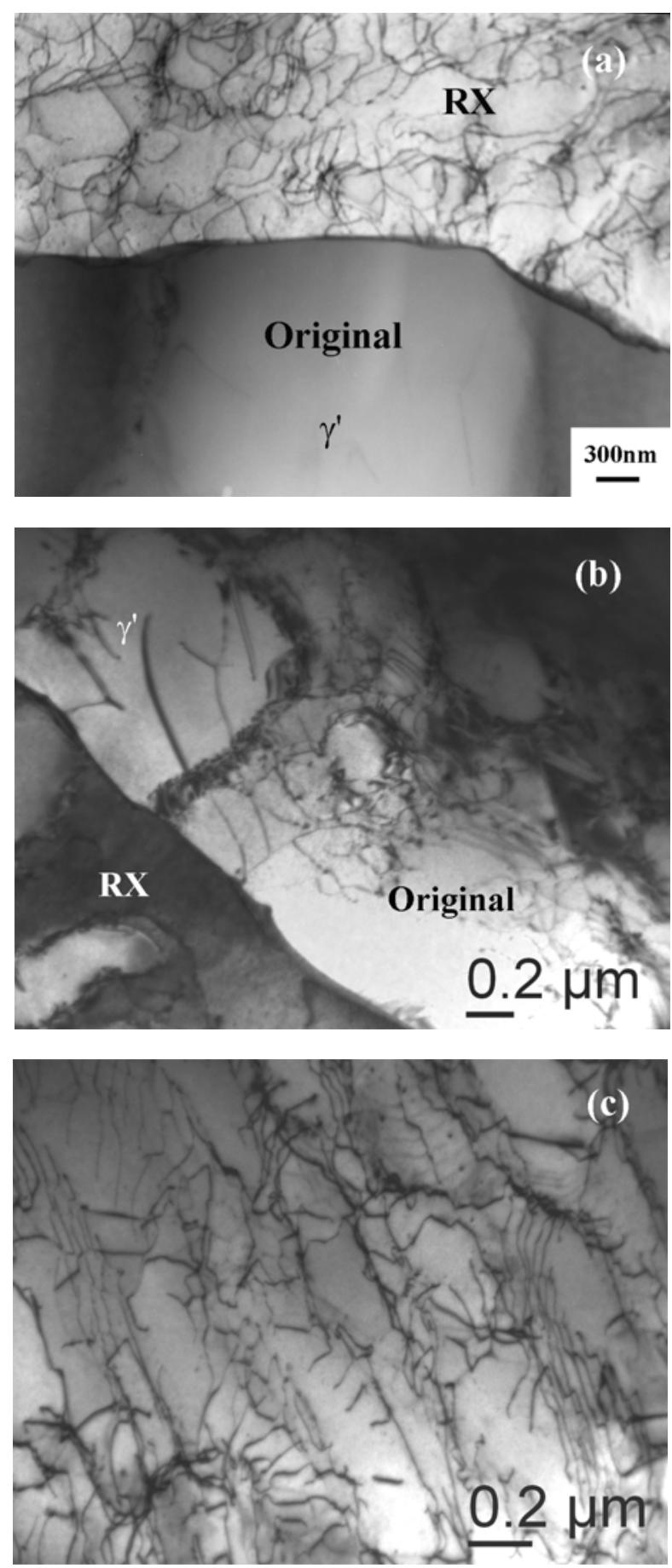

Figure 10: TEM micrograph in specimen interrupted at the tertiary creep stage (point “3” in Figure 3b). Dislocation pattern in the vicinity of the grain boundary: (a) RX and (b) the original DS material. (c) Rafted $\gamma^{\prime}$ in the original DS material far from the $\mathrm{RX}$ region. dislocation density in the original DS material. Work-hardening during creep therefore occurred. The increasing of creep rate due to the slow propagation of these grain boundary cracks was balanced by the reduction of creep rate due to the work hardening effect in the material.

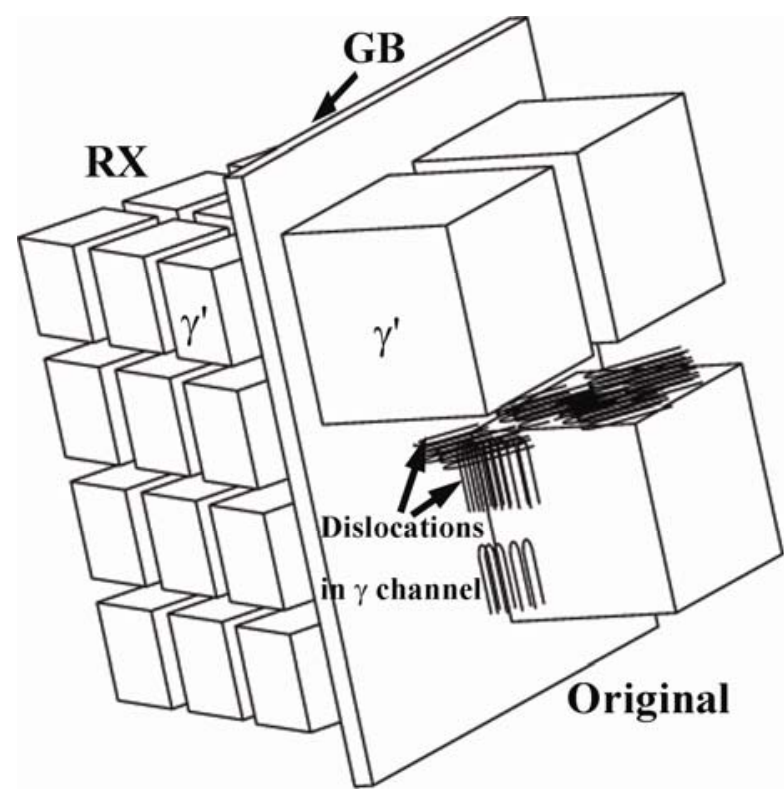

Figure 11: Schematic of dislocation arrangement at the RX grain boundary that resulted in the dislocation tangle.

The propagation of cracks along the transverse $\mathrm{RX}$ grain boundary into the original DS material (Figs. 9b and 9c) induced the tertiary creep stage. The accumulated work hardening and vacancy accumulation also resulted in the formation of voids and cracks at transverse segment of the original DS grain boundaries (Fig. 9d). In this case, the stress carried by the remaining material is significantly increased, which resulted in the accelerated creep rate and the final failure. Therefore, the tertiary creep regime was very short for specimens containing local RX.

The results of creep rupture tests shown in Figure 2 can therefore be interpreted by the above creep mechanism analysis. The load bearing capability of the recrystallized region was very low. Crack initiated and propagated rapidly in the RX region during the early stages of creep. This resulted in the linear reduction of the creep rupture life with the increase of the TRF. 


\section{Conclusions}

The present work indicates that the high temperature creep property is very sensitive to the local RX induced by surface deformation and the subsequent heat treatment. An almost linear reduction of the creep rupture life was observed with the increase of the TRF.

Comparing with "good" specimen, a slight increase in the creep rate of the RX specimen was observed at the end of the primary creep stage due to the initiation of the micro-voids and cracks at the RX grain boundaries.

The secondary and tertiary creep regimes of RX specimens were shorter than those of "good" specimens. The secondary creep regime in the RX specimens was dominated by the propagation of cracks along the transverse grain boundaries in the RX region. Tertiary creep which led to the final failure of the specimen occurred rapidly as soon as the cracks propagated into the original DS material.

\section{References}

1. Chester T. Sims, Norman S. Stoloff and William C. Hagel, eds., Superalloys II, vol. 1, (New York, John Wiley \& Sons, Inc., 1987), 189.

2. Q.Y. Huang and H.K. Li, Superalloys (Beijing, Metallurgy Industry Press, 2000), 213-226.

3. D.C. Cox, B. Roebuck, C.M.F. Rae and R.C. Reed, "Recrystallization of Single Crystal Superalloy CMSX-4," Mater. Sci. Technol., 19 (2003), 440-446.

4. R. Bürgel, P.D. Portella and J. Preuhs, "Recrystallization in Single Crystal Nickel Base Superalloys,” Superalloys 2000, ed., T.M. Pollock, R. D. Kissinger, R. R. Bowman, K.A. Green, M. McLean, S. Olson, and J.J. Schirra (New York, TMS, 2000), 229-238.

5. S.D. Bond and J.W. Martin, "Surface Recrystallization in a Single Crystal Nickel-Based Superalloy,” J. Mater. Sci., 19 (1984), 3867-3872.

6. L. Wang, G. Xie, J. Zhang and L.H. Lou, “On the role of carbides during the recrystallization of a directionally solidified nickel-base superalloy,” Scripta Mater., 55 (2006), 457-460.
7. Y.R. Zheng, Z.C. Ruan, S.C. Wang, "Surface Recrystallization of DZ22 and Influence on the Creep Properties,” Acta Metallurgica Sinica, 31 (1995), 325-329.

8. T. Khan, P. Caron, Y.G. Nakagawa, "Mechanical Behavior and processing of DS and Single Crystal Superalloys," J. Met, (1986), 16-19.

9. C.Y. Jo, H.M. Kim, "Effect of Recrystallization on Microstructural Evolution and Mechanical Properties of Single Crystal Nickel based Superalloy CMSX-2,” Mater. Sci. Technol, 19 (2003), 1671-1676.

10. C.Q. Sun, C.H. Tao, N.S. Xi, W. F. Zhang and C.X. Wu, "Directionally Solidified Non-hafnium Superalloy and Its Overload Mechanical Damage,” Materials for Mechanical Engineering, 25 (2001), 4-7.

11. D.L Wang, "Recrystallization Investigation of Several Nickel Base Superalloys,” Ph. D. thesis, Institute of Metal Research, (2006), 42.

12. G. Xie, L. Wang, J. Zhang, L.H. Lou, "Influence of recrystallization on the high temperature properties of a directionally solidified Ni-base superalloy,” Mater. Metall. Trans. A, 39A (2008), 206-210.

13. M. Okazaki, I. Ohtera and Y. Harada, "Damage Repair in CMSX-4 Alloy without Fatigue Life Reduction Penalty,” Metall. Mater. Trans. A, 35A (2004), 535-542.

14. B.C. Yan, J. Zhang and L.H. Lou, "Effect of Carbon Addition on the Transverse Properties of a Directionally Solidified Superalloy,” Mater. Sci. Technol., In press.

15. T.M. Pollock and A.S. Argon, "Creep Resistance of CMSX-3 Nickel Base Superalloy Single Crystals,” Acta Metall. Mater., 40 (1992), 1-30.

16. D. McLean, "Dislocations, Vacancies and Solute in Grain Boundaries,” Can. Met. Quart. , 13 (1974), 145-153.

17. A. Epishin and T. Link, "Mechanisms of High Temperature Creep of Nickel-Base Superalloys under Low Applied Stress,” Superalloys 2004, ed., K.A. Green, T.M. Pollock, H. Harada, T.E. Howson, R.C. Reed, J.J. Schirra, and S, Walston (New York, TMS, 2004), $137-143$. 